\title{
A APROPRIAÇÃO DA HISTÓRIA COMO FERRAMENTA DE MARKETING
}

\author{
Márcia Paula Migliacci \\ Empresa de Turismo do Município do Rio de Janeiro - RIOTUR \\ márcia.riotur@gmail.com
}

\section{Resumo:}

Este texto trata da apropriação da História pelo marketing turístico, função que tem, entre outros objetivos, o de promover e divulgar um destino. Para analisar o uso dos textos históricos para esse fim se baseia nas questões colocadas pelo livro de Roger Chartier, História Cultural - entre Práticas e Representações. Neste livro, Chartier analisa um conjunto de práticas e objetos culturais e reflete sobre o ofício de historiador. Este artigo trata das questões referentes ao conceito de representação, discutido no livro, e sua relação com o real.

Palavras-chave: $\quad$ Apropriação; Marketing; Representação; Real.

\begin{abstract}
:
This paper deals with the appropriation of history by the tourism marketing, a task that has, among other targets, to promote and disseminate a destination. To analyze the use of historical texts for this purpose based on the issues raised by the book of Roger Chartier Cultural History - Between practices and representations. In this book, Chartier examines a set of practices and cultural objects and reflects on the historian's craft. This article deals with issues relating to the concept of representation, discussed in the book, and its relationship to the real.
\end{abstract}

Keywords: Appropriation; Marketing; Representation; Real. 


\section{INTRODUÇÃO}

A cidade do Rio de Janeiro, no jargão da área do turismo, é um destino turístico. Na promoção e divulgação desse destino a cidade é reconhecida como produto. Um produto que se quer divulgar e promover junto aos órgãos competentes do mercado: os operadores (que representam a venda no atacado) e os agentes de viagem (no varejo).

A área de Marketing utiliza várias ferramentas para colocar esse produto no mercado, sempre alerta para divulgar as características desse produto sob uma luz vantajosa e para promover os seus melhores aspectos - não só a esses revendedores, como para o consumidor final - o viajante/turista/consumidor.

Numa apresentação recente para operadores de turismo na França as primeiras telas de Power point (o programa Microsoft PowerPoint permite que os usuários combinem texto, gráficos e multimídia em uma apresentação de slides), ressaltaram: a exuberante personalidade da cidade, seu cenário de extrema beleza, sua população alegre e descontraída, a terra do samba e bossa-nova, metrópole sofisticada, uma vibrante vida noturna, cidade de cultura e história, vida ao ar livre, hotéis de diferentes categorias e agentes de viagens competentes para bem receber o turista.

Numa tela subsequente ainda foi enfatizado que o Rio tem muitas vantagens a mais como produto, entre elas: o destino turístico mais importante do país, infraestrutura urbana e moderna e centro de cultura e lazer.

Foram apresentadas, nessa ocasião, as estratégias de marketing que foram criadas para melhor receber os turistas dos Jogos Olímpicos, tais como: melhoria das atrações turísticas, pesquisa de recursos inéditos na cidade para criar novas atrações turísticas, atração de novos eventos de qualidade para o Rio, criação novas atrações culturais e melhoria dos serviços e da informação turística, além de criação de aplicativos para celular, facilitadores da circulação dos turistas pela cidade.

O turismo é uma atividade movida pela emoção. Quando nos encontramos no trabalho de divulgação do Rio, em outras cidades ou países, encontramos pessoas que comentam - com os olhos brilhando - “meu sonho é conhecer o Rio de Janeiro! ”. Quando já estiveram na cidade nos saúdam como velhos amigos, dividindo a emoção de sua visita. Em outros casos se aproximam da foto - geralmente colocada em destaque no estande no qual trabalhamos - e se posicionam ao lado da reprodução da 
estátua do Cristo Redentor - comentando, emocionados, “eu estive aqui! ”, donde se depreende que ao visitar o Rio, o sonho se realizou.

A decisão na escolha de uma viagem baseia-se em premissas intangíveis. É por essa razão que o chamado à beleza do cenário, à aventura, ao romance é tão efetivo. Baseia-se, como vimos, em sonhos e desejos.

Atualmente o turista não quer só visitar um lugar, quer também uma experiência diferente, descobrir um recanto escondido, só dele, que lhe proporcione a emoção procurada.

É o chamado Turismo de Experiência. Muitos jovens saem de mochila nas costas "descobrindo" novos lugares, tornando-os "seus". Essas experiências acrescentam um sabor a mais ao produto turístico. O próximo viajante vai também procurar um pequeno detalhe que é só seu. Sempre a emoção e o sonho comandando a ação. Conhecer a história do destino turístico dá um sabor singular à procura do viajante por algo especial, experimentar os diversos tempos da história num destino pode ser uma experiência enriquecedora.

Para se comunicar com os agentes de venda e com o consumidor final as ações de marketing são variadas. $\mathrm{O}$ marketing se dirige ao mercado em algumas frentes. $\mathrm{O}$ destino turístico tem uma imagem que deve ser constantemente preservada, há o trabalho contínuo de equilibrar as notícias negativas de um destino através da divulgação de notícias positivas do mesmo, com releases e ações de relações públicas. Convidam-se agentes de viagens e operadores, num tipo de viagem denominada de Fam trip (viagem de familiarização) e jornalistas (Press trips), onde a estrutura e os serviços e, obviamente, as atrações da cidade são apresentadas. A Assessoria de Comunicação produz informações em formas de releases com novidades sobre a cidade e informações positivas (vale observar que a imprensa notícia regularmente (em todo o mundo) casos de terrorismo e de violência nas cidades/destinos turísticos), portanto é um trabalho ininterrupto.

Produzem-se folhetos e guias para distribuição (alguns dirigidos a agentes, outros ao turista) impressos e publicações digitais como sites e aplicativos. Como já citei, há aplicações de todos os tipos que informam o turista final sobre como se movimentar na cidade.

Criam-se filmes, brindes, ações promocionais, workshops. A empresa de turismo e os conventions bureaux participam de feiras para o encontro com operadores e agentes, que tem dias de visita específicos e separados para o consumidor 
final. Há feiras destinadas à atração de eventos e congressos para a cidade. Nessas feiras o destino turístico promove e divulga suas instalações e hotéis para associações, agentes de eventos, diretores de empresas que procuram locações para seus eventos.

O material usado (i) para a promoção tem que carregar informações substanciais para vários públicos, como se viu. A ênfase em determinados pontos de vantagem de cada produto varia de acordo coma percepção e o objetivos de marketing de cada destino turístico.

É disso que vamos tratar adiante.

O livro de Roger Chartier, Entre Práticas e Representações, analisa vários momentos da prática historiográfica, discutindo o ofício do historiador e os múltiplos conceitos que compõem essa prática. Diversas questões e posicionamentos são discutidos nos oito ensaios do livro.

Chartier salienta de que a história cultural tem por objetivo identificar o modo como, em diferentes lugares e momentos, "uma determinada realidade social é construída, pensada e dada a ler" (CHARTIER, 2002:17). Explica que um dos caminhos diz respeito a sua forma de classificar, dividir e organizar o mundo social numa forma de percepção do mundo real. Esse tipo de esquema cria figuras dando sentido ao presente e decifrando o espaço.

Ao falar de representação nos dá um panorama que se ajusta ao trabalho da inserção da história num plano de promoção da cidade: “as correpresentações assim construídas, embora aspirem a universalidade de um diagnóstico fundado na razão, são sempre determinadas pelo interesse do grupo que as forjam”. (CHARTIER, 2002)

Essa abordagem busca conceber as representações que os grupos fazem e seus objetivos nessa práxis. Nem sempre é possível percebê-las pois vão existir na qualidade de representações. Chartier discute a situação do real, que existe, mas que não existe ao mesmo tempo, substituído por uma versão conveniente a uma determinada situação.

No texto O mundo como representação, Chartier cita Michel Foucault sobre a o sentido que este dá ao conceito de “ apropriação social dos discursos”, como um dos maiores procedimentos através dos quais os discursos são dominados e confiscados. "Pelos indivíduos ou instituições que se arrogam o controle exclusivo sobre eles". (CHARTIER, 1991:180) 
Chama a atenção também sobre a necessidade de atenção às redes de prática que organizam "os modos, histórica e socialmente diferençados, da relação aos textos". (CHARTIER: 1991:181)

Observei que ao utilizar dados históricos na composição de materiais promocionais fazendo com que fatos ou períodos, ao serem pinçados para uma determinada publicação ou fim promocional, se destaquem alguns fatos, em detrimentos de outros, ou ignora-se certos andamentos da história, ou ainda se elaboram novas realidades para aquela situação.

Chartier observa que ao tentar compreender certas formas e motivos de uma determinada representação do mundo social “à revelia dos atores sociais, traduzem suas posições e interesses, objetivamente confrontados e que, paralelamente, descrevem a sociedade tal como pensam que ela é, ou como gostariam que fosse”. (CHARTIER, 1991:19)

\section{MARKETING TURÍSTICO E HISTÓRIA}

Na década de 1990, a Cidade do Rio de Janeiro passou por um evento traumático: dois arrastões seguidos na praia de Ipanema. A cobertura da imprensa foi enorme. A surpresa foi ver essa alegre e ensolarada cidade sob o signo da violência. Parece até estranho, nos dias de hoje, comentar esse assunto, já que a violência parece ter-se tornado assunto trivial na cidade.

No entanto a repercussão e a continuação de notícias negativas sobre o Rio tiveram um impacto enorme, no que era o destino turístico mais popular do país e da América do Sul.

O assunto foi muito debatido nos meios turísticos pelo baque que causou no fluxo de visitantes e pelo dano à imagem da cidade. O produto que se vendia sozinho passou a necessitar de estratégias precisas de marketing.

No Plano Estratégico da cidade, criado pela Prefeitura, discutiu-se, na área correspondente ao turismo, a recuperação da imagem da cidade e de seus atrativos, além de, obviamente, medidas de segurança, indispensáveis àquele momento.

A cidade foi completamente inventariada, seus recursos turísticos e produtos analisados. Chegou-se a um diagnóstico e criou-se um plano denominado Plano 
Maravilha com ações contemplando as diversas áreas de marketing já comentadas anteriormente.

Algumas surpresas surgiram desse inventário. A cidade possuía mais atrativos culturais do que naturais, diferentemente daquilo que era promovido anteriormente. Dirigiu-se toda a comunicação para promover essas novas facetas do Rio, enfatizar a promoção de seus ícones (símbolos da cidade como o Pão de Açúcar e estátua do Cristo Redentor/Corcovado) e da sua exuberante natureza. Os canais usados foram os mais diversos possíveis: anúncios, RP, filmes, folhetos, cartazes, campanhas para o turista, campanhas para o agente, brindes, cartazes etc.

Na criação do material tanto a agência que criava, como o pessoal envolvido na promoção da RIOTUR, redescobriram a cidade, sua história e seus encantos.

A resignificação da apreensão da história na sua construção para o material promocional se colocou como indicado na obra Entre Práticas e Representações por Roger Chartier, numa nova percepção e compreensão da história da cidade, e por consequência da cidade dos dias de hoje "graças as quais o presente pode adquirir sentido, o outro tornar-se inteligível e o espaço a ser decifrado”. (CHARTIER, 1991:17)

A primeira frase do folheto mais importante para o trade turístico (trade: é assim denominado o negócio de turismo de forma mais ampla) - o folheto Trade, tinha uma frase de Fernão Cardim, Tratados da Terra e gente do Brasil "O Arquiteto do mundo...”. (CARDIM, 2009:28) Nesse folheto eram apresentadas as atrações da cidade para os agentes de viagens e operadores.

Observa-se que a apropriação da história pelo marketing não se refere somente ao uso do conteúdo, se refere a um saber fazer, podendo-se dizer que essas apropriações nos mostram a pluralidade das compreensões e da liberdade criadora dos agentes.

A outra referência histórica (do mesmo folheto) era no texto referente ao Jardim Botânico, que citava a fundação do parque pelo Príncipe-Regente D. João VI (ii). O folheto em questão era formato A4 e além deste, foram criados dezesseis outros folhetos menores, no formato10,5X21cm, nos temas: Museus, História, Arquitetura, Esportes, Gastronomia, Ritmos, Santa Teresa, Baía de Guanabara, Lagoa Rodrigo de Freitas, Natureza, etc.

O primeiro a esgotar foi o de História.

A história do Rio, (neste pequeno folheto) foi abordada em dois períodos: da fundação a 1989, dessa data a 1960, data da mudança da capital para Brasília. 
A escolha dos períodos históricos e sua divisão podem ser vistos como representações da história da cidade, uma forma de contar, de criar uma realidade conveniente àquele espaço e momento.

O folheto termina com um verso de Manoel Bandeira, Louvação do Rio de Janeiro, cujo último verso diz: "Cidade de sol e bruma/ Se não és mais capital/ Desta nação/ não faz mal: Jamais capital nenhuma/ Rio, empanará teu brilho/ Igualará teu encanto/ Louvo o Padre/ louvo o Filho/ E louvo o Espírito Santo”. (HISTÓRIA,1999)

Eu sempre ficava com os olhos marejados ao ler o poema e me impressionou saber que causava esse mesmo efeito em outras pessoas. A realidade social daquele momento construída e criada, pensada e dada a ler, chegava com seus significados ao início do século XXI (o folheto é de 1999)?

Houve a reimpressão do folheto História, Museus, Arquitetura e Natureza e Baía de Guanabara, indicando que os atrativos ali publicados despertavam interesse e atenção não só do consumidor como dos agentes/operadores de viagens.

$\mathrm{Na}$ fase seguinte, alguns anos depois, constatou-se que a reimpressão de um número elevado de folhetos não era funcional. Criou-se um novo folheto trade, mesmo formato A4 do anterior. O importante desse formato é a possibilidade de colocar fotos em tamanho grande que produzem um significativo impacto visual. Neste folheto apresenta-se a cidade à escolha do visitante. "Qual é o seu Rio?” É a pergunta/título do folheto, já que existem tantas facetas da cidade para se descobrir, cada qual podendo se adequar ao gosto do visitante. A cidade - e o marketing - descobriam seu próprio produto. Um produto que podia perguntar ao consumidor ou agente, se ele preferia cultura, ou a vida noturna, ou as praias ou um passeio pela floresta.

Neste não há menção de história. É um folheto que apresenta as atrações da cidade para auxiliar a venda do operador/agente. Os folhetos seguintes contemplaram: História/ Cultura e Natureza. Todos A4, com a ideia de substituir os folhetos anteriores menores por um formato de maior impacto.

O folheto Histórico-Cultural foi extremamente apreciado e muito solicitado. Nele a divisão da história do Rio foi feita a cada 100 anos. Títulos internos: Nasce o Rio, O Rio se Expande, O Rio se Edifica, O Rio se Transforma. No final de cada período o resultado em patrimônio, artes e logradouros de cada período, era comentado.

Novamente a ideia da verdade histórica é desmontada. A narrativa dos eventos da cidade segue um padrão escolhido pelo marketing onde se incluiu o espaço cultural (a necessidade de juntar os dois temas cultura e história em um folheto + a descrição 
dos bens patrimoniais da cidade que estariam abertos à visitação) e se conta a história do período.

O folheto seguinte Natureza abordou os recursos naturais do Rio, citando o Padre jesuíta José de Anchieta nas suas Cartas, "É a mais airosa e amena baía que há em todo Brasil” (NATUREZA, 4) explicando a chegada dos portugueses na Baía de Guanabara. Há ainda o histórico da ocupação da baía durante os anos seguintes. Na Baía de Sepetiba há referências aos sambaquis ali encontrados. Abundam no folheto as referências históricas referentes a todos os atrativos naturais.

A história dos atrativos naturais do Rio se torna uma narrativa. Sendo narrativa é literatura e ficcional? A escolha de um tema que apresentasse a espetacular natureza do Rio de Janeiro foi acompanhada de um histórico que tornaria o produto mais interessante ao visitante.

Gostaria de observar que estamos comentando materiais do final da década de 1990 aos dias de hoje.

Paralelamente ao período da execução desses folhetos, foram criados na RIOTUR os Polos Turísticos e Gastronômicos em várias regiões da cidade. O objetivo dos polos era reunir em associação empresários e profissionais da cultura, gastronomia, comércio, serviço, turismo e lazer de cada região da cidade. A ideia era de fortalecer o associativismo e promover o desenvolvimento de regiões que muitas vezes não eram assistidas pelo poder público provocando a evasão da iniciativa privada. Há polos na Zona Sul, Norte, Centro e Zona Oeste.

Na folhetaria inicial de cada um desses polos havia uma apresentação da região em questão. Por exemplo: o Polo da Praça XV foi chamado de Polo Histórico, Cultural e Gastronômico da Praça XV, denominada de Coração do Rio, apresentava alguns edifícios importantes na história da cidade, descrição do casario e comércio, com sugestões de passeios e lazer no local. Sugere-se ali a existência de um lugar aprazível para o lazer com uma ideia de um passeio pela história.

A apropriação das informações históricas tem uma finalidade: a de promover e divulgar a associação, principalmente, de restaurantes de uma determinada localidade.

No de Botafogo, que se denomina: Polo Turístico e Gastronômico de Botafogo, apresenta-se Botafogo com aura de cultura, ao mesmo tempo ressaltando a bagagem aristocrática de suas antigas mansões.

A história, nesse caso, ajuda a vender restaurantes de cada região com uma pitada de sonho e simbolismo, construindo uma representação daquela realidade. 
Num período posterior um novo folheto A4 é criado para o trade. Não há menção de história, já que a percepção da ferramenta história como instrumento de venda não foi reconhecida. A única menção histórica é na descrição da fundação do Jardim Botânico, onde o Príncipe Regente D. João é chamado de imperador, aumentando a aura de majestade do primeiro membro da família real a governar o Brasil no Rio de Janeiro. Há também uma chamada no verbete sobre o Pão de Açúcar sobre um filme que versa sobre o pioneirismo da instalação do bondinho para sua inauguração em 1912.

Voltamos ao assunto da apropriação da história pelo marketing só que nesse caso a apropriação constrói uma nova realidade e a história se transforma efetivamente em ficção.

No mesmo período a RIOTUR em associação com o Guia Lonely Planet lançou um guia de viagem de bolso. As publicações da Lonely Planet são reconhecidas por sua abordagem em primeira mão dos destinos, a praticidade de seus mapas e o comprometimento em dar aos viajantes a melhor informação. O guia reserva duas páginas (é um pequeno guia de bolso) à história da cidade descrevendo sua fundação, as lutas iniciais com os franceses, a instalação das ordens religiosas, completando com a descrição de igrejas e monastérios. Fala da descoberta do ouro no século 18 e do crescimento da economia na cidade. Cita a construção do aqueduto da Carioca e das fortificações da cidade. Cita a mudança da capital da colônia para o Rio e a chegada da família real portuguesa em 1808. Chega até a mudança da capital para Brasília. O que é bastante para um pequeno guia.

É fácil de ler, mas não tem os elementos emocionais que uma publicação feita na cidade poderia ter. Os guias têm a função de dar informações práticas para o viajante. Essa narrativa econômica e sucinta percorre a história da cidade criando uma realidade de bolso, conveniente aos propósitos do guia. É criação de mais uma realidade, uma interpretação da história do Rio de Janeiro.

Costuma-se ter um folheto dirigido ao consumidor, o turista, o visitante da cidade. Em geral são folhetos leves, ou folders (folhas A4 com três dobras). Apresentase as praias em geral gastronomia em geral, arte e cultura, etc, não há menção de história. O visitante recebe um esboço dos atrativos da cidade.

A RIOTUR publica há mais de vinte anos um pequeno guia que já foi bimestral e, atualmente, é semestral. No seu índice se encontram as áreas verdes da cidade, passeios, praias, Rio histórico e outras opções. Há informações sobre compras, 
gastronomia, centros culturais, vida noturna, etc. Ainda possui listagem de hotéis e serviços de transporte.

No item Rio Histórico são listadas as fortalezas da cidade, cada uma com seu verbete e localização. Os verbetes, breves, em virtude do formato do guia, dão um esboço do atrativo mencionado. O da Fortaleza de São João merece interesse pois associa a construção do forte a Estácio de Sá e à fundação da cidade. O que não é inexato. $\mathrm{O}$ forte que Estácio fez instalar era de taipa e madeira e foi um pequeno reduto de resistência dos portugueses. O que se visita hoje é uma fortaleza construída e reforçada durante os séculos seguintes e que era considerada de máxima importância para a defesa da cidade, pois cobria, junto com a Fortaleza de Santa Cruz, a entrada da Baia de Guanabara.

A questão do que é real se coloca novamente. O propósito do guia é alcançado: informa a localização, denomina o atrativo como a primitiva Fortaleza de São João e dá os dados necessários para a visitação. Esse fragmento da história pode ser considerado um fazer, uma criação para uma necessidade moderna. Questiona-se, no entanto, se está ligado à verdade que a história quer transmitir. O sujeito cria e elabora a história que convém a um determinado propósito. Mas não se apropria de sua forma completa, universal e sim dinamiza seu uso para um fim determinado.

Além das fortalezas da cidade o guia lista as igrejas e, novamente, é feita uma seleção do que apresentar. As mais antigas? As de arquitetura singular? As de trabalho de ornamentação interna mais significativa? Novamente existe uma seleção, uma escolha e um fazer.

No item Rio Histórico constam também os edifícios do Paço Imperial, a Praça Quinze, a Ilha Fiscal, a Ilha de Paquetá, o Monumento a Estácio Sá, o Prédio do Iphan, o Palácio Tiradentes e o Theatro Municipal. Não esquecer que há ainda listagem de centros culturais e museus, que poderiam estar na lista do Rio Históricos já que, em geral, são prédios do patrimônio da arquitetura da cidade. No guia também consta uma lista de atrações imperdíveis e de passeios.

Nessas classificações utilizadas no Guia Rio/Visit Rio podemos ver as representações ali selecionadas como construções que os grupos fazem sobre suas práticas. Mas como observa Chartier, em Histórias das Mentalidades "aquilo que é real, efetivamente não é (ou é apenas) a realidade visada pelo texto, mas a própria maneira como ele cria, na historicidade da sua produção e na intencionalidade da sua escrita”. (CHARTIER, 2002:63) 
A Prefeitura está revitalizando o porto do Rio de Janeiro. A Companhia de Desenvolvimento Urbano da Região do Porto do Rio de Janeiro (Cdurp), é a gestora da prefeitura na Operação Urbana Consorciada Porto Maravilha.

Há um passeio organizado pelo Sebrae com apoio da RIOTUR, pelas áreas do porto que já passaram pela revitalização. O passeio denomina-se Tour da Experiência e promove a visita a vários pontos dessa área revitalizada incluindo atrativos de áreas próximas como o Palácio do Itamaraty, o Paço Imperial, o Palácio Duque de Caxias, entre outros.

Os lugares que se localizam na região do porto como a Pedra do Sal, o Cais do Valongo e a própria Praça Mauá, com seus dois novos museus, o Espaço Meu Porto Maravilha, tem recebido bastante atenção da parte do Porto Maravilha e da imprensa em geral.

Desde o início das obras do porto com as escavações arqueológicas que foram feitas no Cais do Valongo a região tem sido ligada ao tema da escravidão no Brasil. No site do Porto Maravilha, no item Cultural, há uma chamada para o tema Herança Africana.

No site o assunto é colocado da seguinte maneira:

Achados arqueológicos motivaram a criação, pelo Decreto Municipal 34.803 de 29 de novembro de 2011, do Grupo de Trabalho Curatorial do Circuito Histórico e Arqueológico da Herança Africana, para construir coletivamente diretrizes para implementação de políticas de valorização da memória e proteção deste patrimônio cultural. Cada um dos pontos indicados pelo decreto remete a uma dimensão da vida dos africanos e seus descendentes na Região Portuária. O Cais do Valongo e da Imperatriz representa a chegada ao Brasil. O Cemitério dos Pretos Novos mostra o tratamento indigno dado aos restos mortais dos povos trazidos do continente africano. O Largo do Depósito era área de venda de escravos. O Jardim do Valongo simboliza a história oficial que buscou apagar traços do tráfico negreiro. Ao seu redor, havia casas de engorda e um vasto comércio de itens relacionados à escravidão. A Pedra do Sal era ponto de resistência, celebração e encontro. E, finalmente, a antiga escola da Freguesia de Santa Rita, o Centro Cultural José Bonifácio, grande centro de referência da cultura negra, remete à educação e à cultura como instrumentos de libertação em nossos dias. 
Lendo o artigo da Professora Maria Cecília Velasco e Cruz denominado O Porto do Rio de Janeiro no século XIX: Uma realidade de muitas faces, observei que o porto do Rio focalizado no artigo tinha uma dimensão diferente dessa ideia de local do legado africano.

Ela informa que o porto "era um enorme complexo de unidades independentes que abarcava diversas ilhas na Baía de Guanabara e se estendia, no continente, da região fronteira ao Paço Imperial até as praias das palmeiras e São Cristóvão”. (CRUZ, 1999:04) Havia diversas docas: Docas da Alfândega e do Mercado, Docas de D. Pedro II, dique da Saúde, Estação Marítima de Gamboa, dois complexos privados de cais e silos e mais de sessenta trapiches, que se sucediam um ao lado do outro da Prainha a São Cristóvão.

Durante o século XIX, de acordo com decretos imperiais e dependendo da mercadoria, não era necessário passar pela Doca da Alfândega, a verificação podia ser feita na água, e depois se levava a mercadoria para os diversos trapiches, que podiam ser de grandes firmas de exportação/importação ou um trapiche particular de pequena escala. Alguns trapiches com o passar dos anos começaram a alfandegar mercadorias e para isso, tinham oficiais trabalhando in loco nesse trabalho. Havia tantas áreas de recebimento que em 1895 o Cônsul Geral da Suécia e Noruega consultou a Associação Comercial se poderia descarregar parte de uma determinada carga em Botafogo e se esse lugar poderia ser considerado com porto. A professora comenta que "a resposta afirmativa dada pela Associação ao Cônsul refere-se explicitamente a fluidez físicas das fronteiras portuárias”. (CRUZ, 1999:16)

Essa longa explicação tem a ver com a imagem que esse porto extremamente movimentado, que gerava oitenta por cento da receita do Império, e que tinha um grau de eficiência bastante significativa, nos apresenta. É uma imagem de movimento, bulício, circulação de pessoas, oficiais da alfândega, donos de trapiches, os muitos funcionários de trapiches, seus proprietários, marinheiros, viajantes, comerciantes locais com artigos para a região, acomodações, locais de alimentação e bares.

Compondo essa imagem temos a do escravo exercendo suas diversas funções na parte que lhe cabia nessa sociedade, não esquecendo que o escravo de ganho poderia comprar sua liberdade, e, em algum momento, engrossar a lista de pessoal em circulação pelo porto (ou portos de recepção e envio de mercadorias) exercendo seu trabalho, já liberto, na área comercial ou em ofícios mecânicos. 
É importante assinalar que as Docas de D. Pedro II foram edificadas por André Rebouças, entre 1871 e 1876, filho de uma escrava alforriada e um alfaiate português, era negro, engenheiro, monarquista, inventor e advogado autodidata e, certamente, durante a construção das docas, parte dessa população que se movimentava pelo porto.

A diversidade de docas e sua área de extensão nos informam da extrema variedade de portos para chegada dos escravos desde a fundação da cidade até 1811, data em que o marquês de Lavradio mandou edificar o cais do Valongo.

Tudo sumiu. Essa visão da atividade comercial do maior porto do Brasil, durante o século 19, foi substituída pela ideia do cais dos escravos (construído em 1811, fechado em 1831). O Cais do Valongo foi reformado em 1843 para receber a noiva de D. Pedro II, passando a chamar-se Cais da Imperatriz. Com a lei Eusébio de Queiroz houve, em teoria, o fim do tráfico de escravos. Consta que a última remessa de escravos tenha sido de 1872, mas, obviamente, não chegando por esse cais, nem nas diversas áreas, já citadas, de atracação, já que havia passado a ser uma atividade fora da lei.

Já foi dito que a reforma do cais, transformando-o no Cais da Imperatriz, foi feita para apagar a realidade do antigo mercado de escravos. No entanto em 1843 ainda se vivia em uma sociedade escravocrata. Se esse foi o caso, podia tentar-se apagar, com a reforma, o antigo local de chegada dos escravos, mas não se apagava a realidade do dia-a-dia daquela sociedade.

O porto, com a chegada da família real, desenvolveu-se num processo acelerado, mais ainda depois da independência. Como comenta a professora Maria Cecília, "a revogação dos monopólios coloniais trouxe para a cidade, um exército de navios e milhares de mercadoria”. (CRUZ, 1999:5)

O conceito de representação aplicado ao caso acima se apresenta como alternativa de compreensão do social da realidade via representação. O que existe nesse caso é o que está representado.

A necessidade de inclusão do negro na sociedade brasileira, e a contribuição cultural da herança africana na formação da cultura brasileira, compondo a história da cidade, motivou a criação dessa representação alternativa da história nesse local específico. No entanto na cidade abundam locais onde circulavam, viviam e morriam escravos na cidade. Eles eram parte da vida do Rio de Janeiro.

Num conto de Machado de Assis denominado Pai contra Mãe, há a história de um rapaz que pegou o ofício de caçar negros fugidos. No início da história Machado comenta "A escravidão levou consigo ofícios e aparelhos, como terá sucedido a outras 
instituições sociais. Não cito alguns aparelhos senão por se ligarem a certo ofício" passando a descrever o ferro ao pescoço, ferro ao pé, máscara de folha-de-flandres etc. e seus usos. (MACHADO, 2016:01)

Ele termina com a seguinte observação: " Os funileiros as tinham penduradas, à venda, na porta das lojas". (MACHADO, 2016) Podendo-se deduzir que era comum encontrar-se esse tipo instrumento em qualquer funileiro da cidade, não especificamente só no porto, próximo do Valongo.

No livro Memórias da Cidade do Rio de Janeiro, o memorialista Vivaldo Coaracy, ao descrever a Lagoa de Santo Antônio, local do atual Largo da Carioca nos revela que a lagoa era considerada lugar distante e por isso foi autorizado a construção de um curtume, que "convinha ser localizada em ponto distante para não incomodar os habitantes". (COARACY, 1965:147) Num dos outros lados vinham índios se banhar e ainda vinham beber os bois de um curral próximo. No local havia uma ermida à invocação de Santo Antônio. Mais tarde chegou a ordem de São Francisco que escolheu esse local para erigir um monastério, isso por volta de 1607. Ele observa que durante mais de dois séculos na face sul da Largo da Carioca entre a rua da Carioca e a ladeira de acesso às igrejas, foi ocupada pelo Hospital da Penitência. Antes disso, foi um cemitério na faixa de terra ás margens da Lagoa os Franciscanos começaram a dar sepultura a seus escravos que faleciam. Por caridade cristã faziam isso a outros cativos da cidade. Segundo Coaracy "naqueles tempos ásperos o escravo era considerado, praticamente, no mesmo plano de animais de trabalho. Quando lhes morria uma "peça", como então se dizia, mandavam-na enterrar em qualquer lugar ermo, como carniça, sem o menor respeito pela sua condição humana”. (COARACY, 1965:165) Diante disso é que os frades decidiram abrir o Campo Santo e cuidar do enterro de escravos que não os seus. Coaracy observa que é por essa razão que se encontravam ossadas humanas durante trabalhos de escavação executados no Largo da Carioca.

Observa-se que Coaracy cita a descoberta de ossadas humanas nos trabalhos de escavação do Largo da Carioca que - naquele momento histórico - (a data do livro é 1965, mas foi escrito alguns anos antes) não provocava ações para escavações arqueológicas no local e/ou questionamento sobre o uso daquele espaço.

A presença do escravo está inserida na história da cidade do Rio de Janeiro em todos os seus momentos, ao longo dos séculos e por toda parte da cidade. Os instrumentos de repressão para lidar com o escravo e o tratamento dado a essa parcela da população fazem parte do tecido da construção da história brasileira. 
Completando com o raciocínio de Chartier, "a relação do texto com o real (que pode definir-se como aquilo que o próprio texto apresenta como real construindo-o como um referente situado no seu exterior) constrói-se segundo modelos discursivos e delimitações intelectuais próprios de cada situação da escrita”. (CHARTIER, 2002:63)

Para esse tour na área do Porto Maravilha foi criado um mapa que compreende a área do porto que já foi revitalizada. No mapa os atrativos são sinalizados por números que são encontrados no verso do mapa com a devida identificação. A região começa a apresentar o surgimento de restaurantes e bares, cujas características reforçam a valorização da culinária nacional com degustação de caipirinha, café feito à moda antiga, bolos tradicionais etc.

Um folheto publicado é, geralmente, o final de uma longa trajetória de planejamento. O que está sendo mostrado como atração é um produto, que pode ter adquirido sua forma durante sua própria concepção.

A região do porto já é um produto que pode ser oferecido: pode-se fazer um tour, existe o mapa, há guias para levar aos pontos turísticos, há alimentação servindo diferentes paladares, existem os pontos turísticos preparados para receber o visitante, e a história pronta para ser contada pelo guia para dar sabor ao passeio. Uma história que gira em torno do tema que foi escolhido para resignificar essa área da cidade.

(i) O material promocional usado se compõe de folhetos, pôsteres, guias, anúncios etc. Abaixo páginas do broadside mostrando algumas peças utilizadas (broadside significa peça publicitária destinada aos públicos internos e intermediários de uma empresa, contendo informações sobre os esforços de comunicação e explicações de como será uma campanha de propaganda e/ou promoção). 

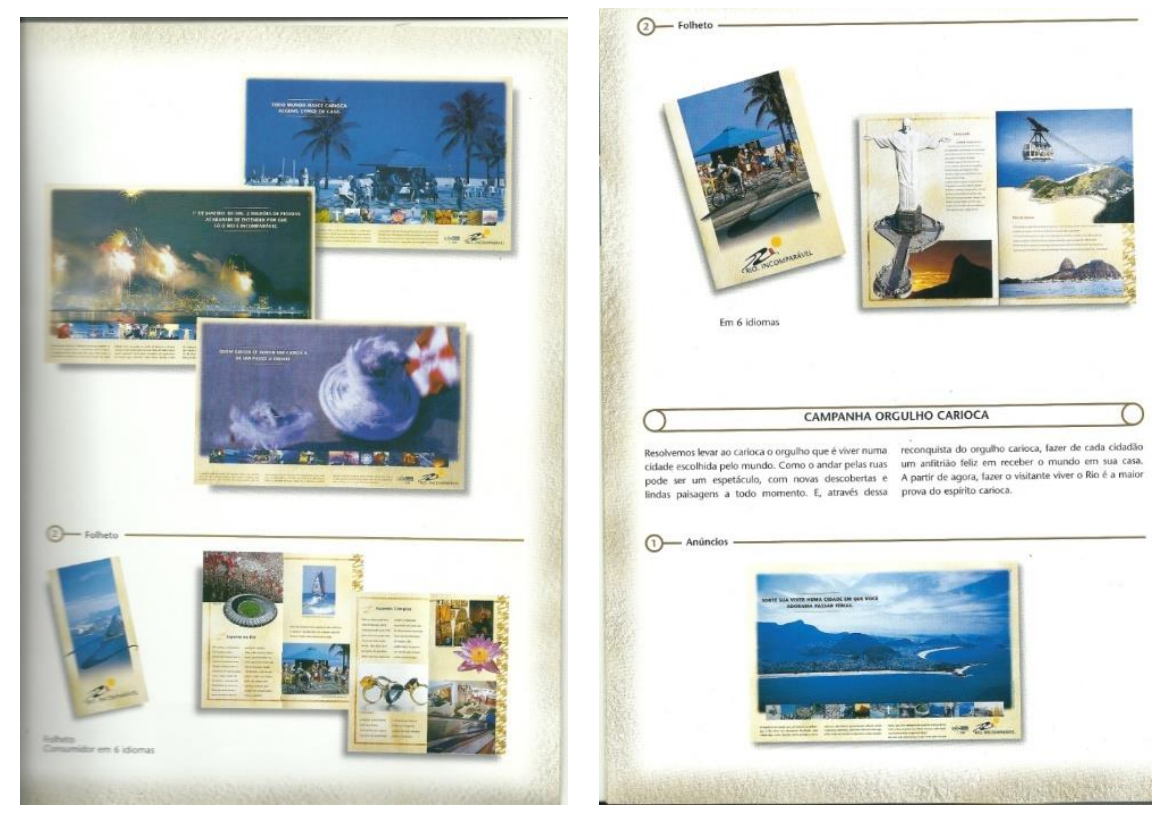

(ii) O nome do Príncipe Regente, nesse folheto, foi usado com a titulagem que teria mais tarde como rei: D. João VI.

\section{REFERÊNCIAS BIBLIOGRÁFICAS}

CARDIM, Fernão. Tratados da Terra e gente do Brasil. Disponível em: $<$ https://books.google.com.br/books=FERNÃO+CARDIM+O+arquiteto\&source $>$.

CHARTIER, Roger. A História Cultural - entre Práticas e Representações. Miraflores: Difel, 2002.

CHARTIER, Roger. O mundo como Representação. Revista das Revistas. Disponível em: <http://www.scielo.br/pdf/ea/v5n11/v5n11a10.pdf>, São Paulo, 1991.

COARACY, Vivaldo, Memórias da Cidade do Rio de Janeiro. Rio de Janeiro: Editora Livraria José Olympio, 1965.

CRUZ, Maria Cecília Velasco e. O porto do Rio de Janeiro no século XIX: Uma realidade de muitas faces. Revista Tempo, v. 8, agosto de 1999. Disponível em: $<$ http://www.historia.uff.br/tempo/artigos_livres/artg8-7.pdf $>$.

GUIA LONELY PLANET, Guia do RIO DE JANEIRO. Edição de 2011. 
MACHADO DE ASSIS, Joaquim Maria. Pai contra Mãe. Biblioteca Virtual do Estudante Brasileiro. Disponível em $<$ http://www.bibvirt.futuro.usp.br $>$. A Escola do Futuro da Universidade de São Paulo, 2016.

PLANO MARAVILHA. Secretaria Especial de Turismo/RIOTUR. Relatório Final do Plano de Turismo da Cidade do Rio de Janeiro, Sede RIOTUR, 1997.

PORTO MARAVILHA. Disponível em < www.portomaravilha.com.br/circuitoherança-africana>, Rio de Janeiro, 2016.

Márcia Paula Migliacci: Graduada em História pela Universidade Gama Filho. Gerente de Promoção Internacional da RIOTUR - Empresa de Turismo do Município do Rio de Janeiro.

Artigo recebido para publicação em: maio de 2016 Artigo aprovado para publicação em: agosto de 2016

\section{Como citar:}

MIGLIACCI, Márcia Paula. A apropriação da história como ferramenta de marketing. Revista Transversos. "Dossiê: História Pública: Escritas Contemporâneas 
de História". Rio de Janeiro, Vol. 07, nº. 07, pp. 235-252, Ano 03. set. 2016. Disponível em: <http://www.e-publicacoes.uerj.br/index.php/transversos>. ISSN 2179-7528. DOI: 10.12957/transversos.2016.25601.

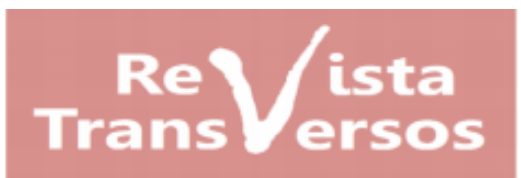

